\section{Why are we so bad at $R$ Gregson treating amblyopia?}

Eye (2002) 16, 461-462. doi:10.1038/

sj.eye. 6700102

The history of medicine is littered with abandoned treatments. Sometimes treatments are abandoned because they don't work well enough, but often they are abandoned because they work well enough but are too much trouble to take. Imagine you have a treatment for a serious disease but you find that only $50 \%$ of patients take it, and that the others prefer to have the disease. Clearly your treatment is no good. It might cure the condition, but the compliance with it is so poor you ought to look for something else. Before the introduction of ivermectin, this was the case with the treatment for onchocerciasis: diethylcarbamazine cured the condition but compliance was poor because it caused such awful dermatitis that it was unacceptable to the patients (later it was also shown to be actually harmful to the retina). One could describe this by saying that the unacceptability of the treatment was greater than the motivation of the patients to protect themselves from the disease. One could, if one wished, formalise this concept and examine it quantitatively. Fortunately we don't have to do this, because it has already been done by behavioural scientists.

Amblyopia is the commonest cause of a visual defect in a child in the UK, and, despite all our efforts, there are still children growing up to become amblyopic adults. We know that patching treatment can work for amblyopia; we all see children whose vision improves dramatically when they have the patching treatment. Why then does patching treatment fail, as it so often does? The answer, as any orthoptist would agree, is compliance. The motivation of the patients (and their parents) to protect themselves from the disease is often outweighed by the adverse effects of the treatment itself.

In Volume 16 issue 2 on pages $150-155$ this problem is examined in detail by Searle, Norman, Harrad and Vedhara, using the formalised protection-motivation theory of behavioural science. The details of the paper make difficult reading, but the conclusions are clear: $18 \%$ of the patients didn't attend for follow-up; only $54 \%$ of those who did come for follow-up had managed to comply fully with the orthoptists' patching regimes; the parents' belief in their own ability to patch their child was low; and the parents' belief in the value of patching was not good.

Perhaps they are right. Parents of amblyopic children are often themselves amblyopes and do not always regard this as much of a handicap. They can, however, usually remember having the patching treatment themselves and are often loath to want to inflict this on their child. Sometimes the child has the upper hand in the relationship and patching treatment causes a lot of friction that the parent would rather do without. The parents concern about amblyopia, and their belief in patching is outweighed by these negative points. There are other problems with patching too-we know that patching disrupts whatever fusion there is and quite often can make the squint worse because of this.

We do, of course have other treatments atropine occlusion is effective if the vision is not too poor, and L-dopa treatment can also be useful. ${ }^{1-4}$ We have, too, different ways of administering the patching, ranging from fulltime occlusion as an in-patient to part-time occlusion at home.

There seem to be three pressing questions, that, despite much research, are still not fully answered:

(1) How significant a problem is amblyopia?

(2) Can we adjust the way that we use our current treatments to improve the outcome?

(3) Can we develop any new treatments that are more acceptable?
Royal College of Ophthalmologists, 17 Cornwall Terrace Regent's Park London NW1 4QW, UK

Correspondence: R Gregson E-mail: Richard.Gregson@ mail.qmcuh-tr.trent 
We tend to scoff nowadays at the attempts by previous generations to treat amblyopia with what were then new-fangled treatments, such as Pleoptics or the CAM stimulator. This is, I think, rather unfair. At least the orthoptists and ophthalmologists of the time recognised the limitations of patching treatment and were looking for a more acceptable solution to the problem. Perhaps we ought to try to emulate them, and try to solve the problem of amblyopia the same way as onchocerciasis has been. Perhaps we should devote all our energies not to arguing about the pros and cons of screening programmes, but to developing a better treatment, one that is complied with and so really does work.

\section{References}

1 Chatzistefanou KI, Mills MD. The role of drug treatment in children with strabismus and amblyopia. Paediatric Drugs 2000; 2: 91-100.

2 Mohan K, Dhankar V, Sharma A. Visual acuities after levodopa administration in amblyopia. J Ped Ophthalmol Strabismus 2001; 38: 62-67.

3 Porciatti V, Schiavi C, Benedetti P, Baldi A, Campos EC. Cytidine-5'-diphosphocholine improves visual acuity, contrast sensitivity and visually-evoked potentials of amblyopic subjects. Curr Eye Res 1998; 17: 141-148.

4 Foley-Nolan A, McCann A, O'Keefe M. Atropine penalisation versus occlusion as the primary treatment for amblyopia. Br J Ophthalmol 1997; 81: 54-57. 